\title{
Three-dimensional MR microscopy of snowpack structures
}

\author{
Toshihiro Ozeki* (1), Katsumi Kose ${ }^{(2)}$, Tomoyuki Haishi ${ }^{(3)}$, \\ Seitarou Hashimoto ${ }^{(2)}$, Shun-ichi Nakatsubo ${ }^{(4)}$, Kouichi Nishimura ${ }^{(4)}$ \\ (1) Hokkaido University of Education, Iwamizawa, Japan \\ (2) Institute of Applied Physics, University of Tsukuba, Tsukuba, Japan \\ (3) MR Technology Co., Tsukuba, Japan \\ (4) Institute of Low Temperature Science, Hokkaido University, Sapporo, Japan
}

\begin{abstract}
A magnetic resonance microscopy technique was developed to visualize and quantify the three-dimensional structure of snowpack. Because the NMR signal from the ice was very weak, we looked at the air space in the snow that was filled with dodecane doped with iron acetylaetonate. Four types of snow were tested: ice spheres, large rounded poly-crystals, small rounded mono-crystals and depth hoar crystals. Among these materials, the depth hoar crystals were the best for the test imaging, since they were sufficiently large and have anisotropic structures. A specific specimen-cooling system was developed to keep the temperature below 0 ${ }^{\circ} \mathrm{C}$. In the experiments 0.5 to 2 hours were necessary to accumulate the signals enough to obtain a $3 \mathrm{D}$ micro-image; the image matrix $128^{3}$, voxel size $200 \mu \mathrm{m}^{3}$ or the image matrix $256^{3}$, voxel size $120 \mu \mathrm{m}^{3}$. The 3D structures of snow were investigated viewing from various angles and cross sections. Comparison with the $2 \mathrm{D}$ data using the conventional thin section method was also carried out and it was attested that the MR microscopy could be a powerful tool to reveal the microstructure of snowpack.
\end{abstract}

Keywords: snow crystal structure, magnetic resonance imaging, three-dimensional structure, dodecane

\section{Introduction}

Microstructure of the snowpack should be better understood because it determines the physical properties of snow. The avalanche release mechanism also depends on the three-dimensional network structure of snowpack. Although thin sections and plane-surface sections have been applied to reveal the snow structures, they have given us only two-dimensional information; therefore, a large number of operations are necessary to reconstruct the three-dimensional structure. Recently, several researches are made to develop new technique getting 3D microstructure of snow. Schneebeli (2000) developed a smart system that consisted of slicing, segmentation and reconstruction of snow samples filled with dimethylphthalate. The 3-D structure of snow could be reconstructed and visualized on the computer within 2 hours. Coléou et. al. (2001) used X-ray absorption tomography to build 3-D high-resolution image of snow $\left(10 \mu \mathrm{m}^{3}\right)$ and obtained the porosity and discrete local curvature of snow.

* Corresponding author address: Toshihiro Ozeki, Hokkaido University of Education, Midorikaoka 2-34-1, Iwamizawa, Hokkaido 068-8642, JAPAN; tel: +81-126-32-0336; fax: +81-126-32-0251; email: oze@iwa.hokkyodai.ac.jp
On the other hand, nuclear magnetic resonance (NMR) imaging, which coupled with the explosive growth of digital computers, is playing an important role in medical imaging over the last several years. The development of NMR imaging has enhanced ability to diagnose and monitor diseases. Because NMR is particularly sensitive to the proton magnetic moment that occurs in water and organic compounds, the mixture of liquid and solid water gives good contrast of image. Edelstein and Schulson (1991) and Eicken et. al. (2000) applied NMR imaging to visualizing of drainage channel within salt-water ice accordingly. Ozeki et. al. (2000) applied the NMR imaging system to snow structures and succeed to visualize the packing of ice spheres $3 \mathrm{~mm}$ in diameter. They tried to look at the depth hoar crystals as well, but failed to reproduce the original structure since the depth hoar layer was disassembled when it was set into the sample holder.

In this paper we introduce the improved NMR imaging technique so as to visualize and quantify the 3D structure of natural snowpack.

\section{Materials and methods}

Magnetic resonance imaging has advanced as a tomographic technique to medical imaging over the last several years. MRI images a NMR signal from 


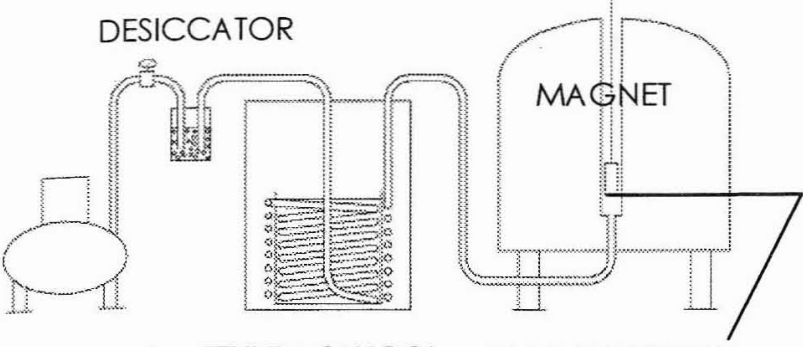

AIR COMP. ETYLEN GLYCOL
SAMPLE HOLDER

Figure 1: Apparatus for MR imaging of snow structure.

the proton magnetic moment. NMR is sensitive to the proton magnetic moment in water and fat, which primarily make the human body. In MR microscopy, the sample of interest is set in a strong, uniform magnetic field with gradient magnetic field that varies linearly. Radio-frequency coils are used to apply an RF magnetic field to the sample and to receive NMR signals from the sample.

In this study three-dimensional microscopic images were obtained with a homebuilt NMR imaging system using a 4.74 Tesla, $89 \mathrm{~mm}$ vertical-bore super-conducting magnet and an actively shielded gradient coil (Kose, 1996). The proton resonance frequency was $202 \mathrm{MHz}$. The phase-encoding directions were the $\mathrm{x}$ - and $\mathrm{y}$ directions and the signal readout direction was the $\mathrm{z}$ - direction.

Since the NMR signal from the ice was very weak, we filled the air space of snow with iron acetylacetonate $\mathrm{C}_{15} \mathrm{H}_{21} \mathrm{O}_{6} \mathrm{Fe}$ doped aniline $\mathrm{C}_{6} \mathrm{H}_{7} \mathrm{~N}$ or dodecane $\mathrm{C}_{12} \mathrm{H}_{26}$, both of which give NMR signal strong enough, a good infiltration property and a low freezing point (about $-6{ }^{\circ} \mathrm{C}$ and $-12{ }^{\circ} \mathrm{C}$ ). Thus, the NMR system images the space occupied with dodecane instead of ice particles. The spin-lattice relaxation time (T1) of the iron acetylacetonate doped dodecane was about $400 \mathrm{~ms}$.

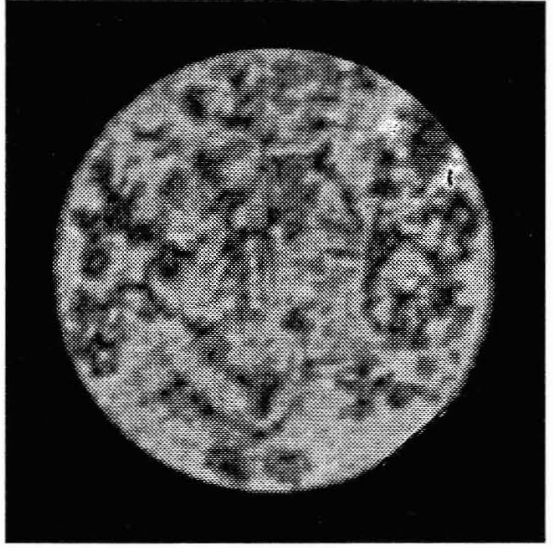

Figure 2: 2D cross-sectional MR image of depth hoar crystals.

Signal accumulations were necessary in order to reduce the noise, and hence it took more than half an hour to obtain one 3D image of snow. So a small acrylic chamber with a double pipe cylinder was constructed to keep the temperature of sample cold enough. A sample holder with dimensions of 24 $\mathrm{mm}$ inner diameter and $100 \mathrm{~mm}$ long was set into the inner cylinder. Cold air, which was kept about $-25{ }^{\circ} \mathrm{C}$ through frozen ethylene glycol, was led into the inner pipe (Figure 1) by the air compressor. The temperature of the sample holder was kept between $0{ }^{\circ} \mathrm{C}$ and the melting point of the dodecane during the measurements.

Four types of snow were tested: ice spheres of about 3-mm in diameter, large rounded poly-crystals, small rounded mono-crystals and depth hoar crystals. The ice spheres were made of water dropping into the liquid nitrogen. Others were taken from the natural snowpack in Hokkaido, Japan. Among these materials the depth hoar crystals were utilized to improve the NMR imaging system, since they were sufficiently large and have anisotropic structures.
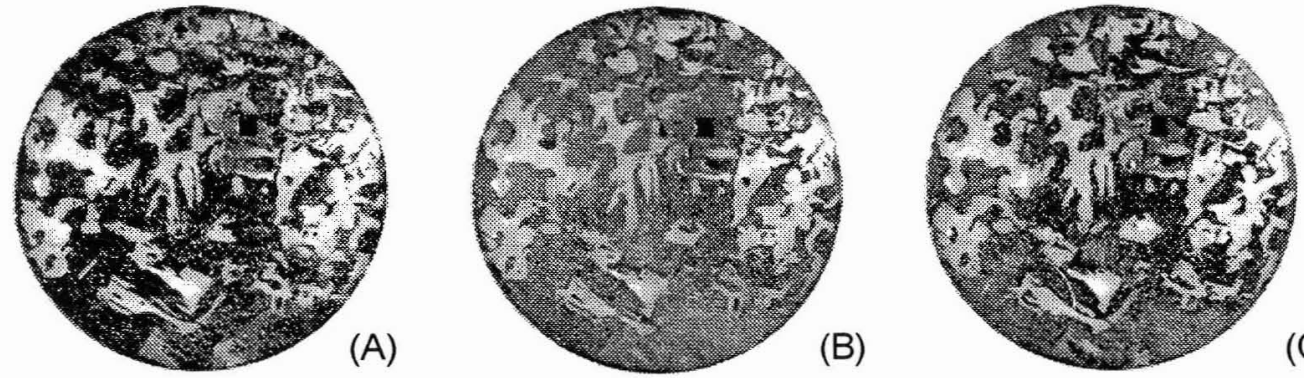

(C)

Figure 3: Section planes of depth hoar. Intervals of (A) to (B) and (B) to (C) are $0.1 \mathrm{~mm}$. 


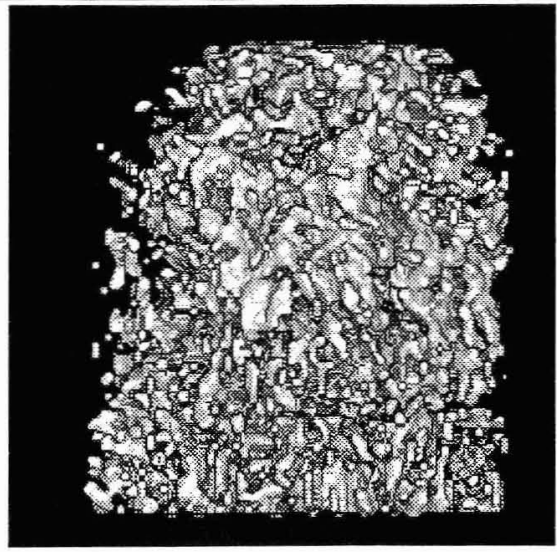

Figure 4: Volume-rendered 3D display of depth hoar (reversal image).

Images were obtained with the following three kinds of sequences; the image matrix $256^{3}$, voxel size $120 \mu^{3}$, the image matrix $128^{3}$, voxel size 200 $\mu \mathrm{m}^{3}$ and the image matrix $64^{3}$, voxel size $400 \mu \mathrm{m}^{3}$. The first one was for the imaging of the small rounded mono-crystals and the last one was used for the continuous measurement aimed to look at snow metamorphism.

\section{Experimental results}

Figure 2 shows horizontal cross-sectional image cut from 3D MR image data of depth hoar layer; field-of-view $(\mathrm{FOV})=25.6 \mathrm{~mm} \times 25.6 \mathrm{~mm}$, image matrix $=128 \times 128$, and slice thickness $=0.2 \mathrm{~mm}$. The depth hoar specimens were filled with iron acetylacetonate doped aniline. Because NMR signal is obtained from aniline and not from the ice, the depth hoar crystals are shown as dark particles or segments in the figure. On the other hand, Figures 3 (A), (B) and (C) show the section planes dyed with sudan-black B using the same sample in Figure 2. The procedure of making thin section is introduced in Hachikubo et. al (2000). Dark area in Figure 3 is the pour space of the depth hoar specimens. Intervals of (A) to (B) and (B) to (C) are $0.1 \mathrm{~mm}$. Since the NMR signal was gained from the voxel of $0.2 \mathrm{~mm}$ thick, the MR image in Figure 2 is reflecting the structure shown in the three section planes in Figure 3. We see the pictures in Figure 3 and 2D image in Figure 2 resemble closely, which indicates that MRI reconstructs the distribution of ice grains accurately. Comparison of the images in Figures 2 and 3 is also useful to determine the threshold brightness, which distinguishes the ice from the filling in NMR images.

Figure 4 illustrates a volume rendered 3D display of depth hoar specimen. Because NMR signal was obtained from dodecane, this was

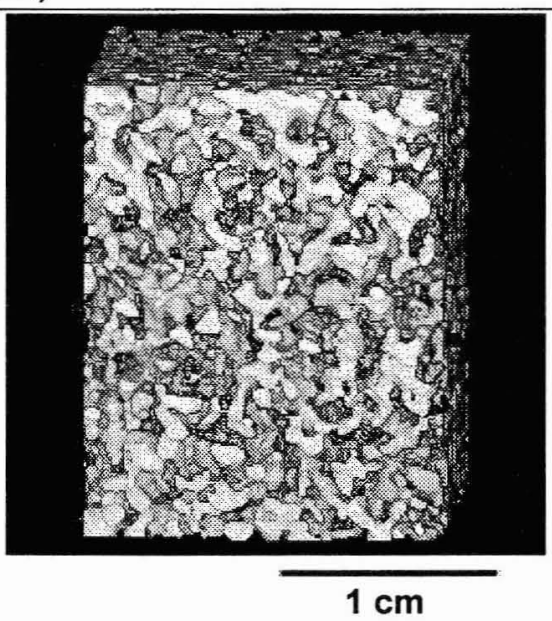

Figure 5: Volume-rendered 3D display of depth hoar (voxel size $200 \mu \mathrm{m}^{3}$ ).

reversal image of the crystals: i.e. depth hoar crystals correspond to void area in the figure. Negative images of the above 3D data were processed and 3D display of the depth hoar is shown in Figure 5 (voxel size $0.2 \mathrm{~mm} \times 0.2 \mathrm{~mm} \times$ $0.2 \mathrm{~mm}$ ). The classical thin section of the depth hoar specimen is also shown in Figure 6. Figure 7 illustrates a volume rendered 3D image of large rounded poly-crystals, and the classical thin section is shown in Figure 8. In Figure 7, we can recognize the 3D structure of large rounded poly-crystals from various viewing angles and cross sections. The grain size of small rounded mono-crystals was smaller than others (Figure 9), then MR image was gained using the sequence of image matrix $256^{3}$. Figure 10 illustrates a volume rendered 3D image of small rounded mono-crystals. Although the higher resolution seems preferable to analyze the bond structure between grains, it is certain the NMR imaging system developed in this study will be a powerful tool to investigate the snowpack structures.

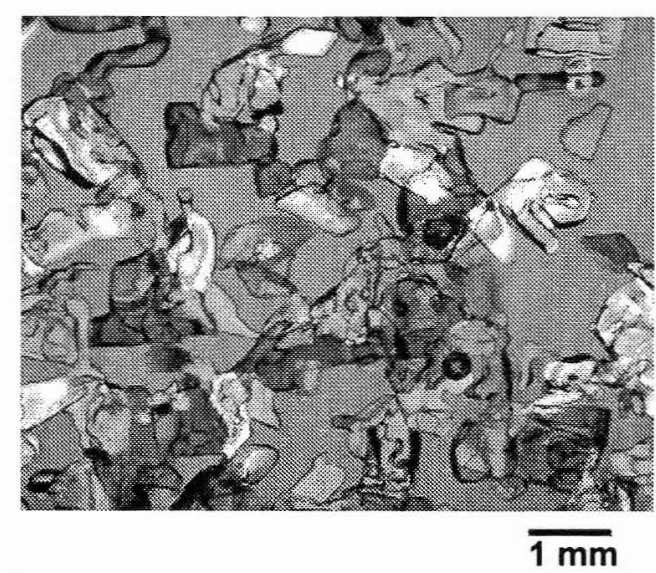

Figure 6: Thin section of depth hoar crystals. 


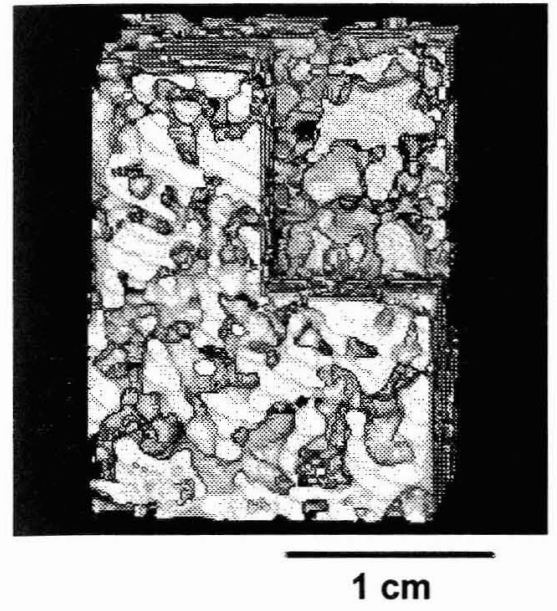

Figure 7: 3D display of large rounded poly-crystals (voxel size $200 \mu^{3}$ ).

\section{Acknowledgements}

We are grateful to Assoc. Prof. A. Hachikubo of Kitami Institute of Technology for his support of sample preparation. We also thank Assoc. Prof. H. Narita of the Institute of Low Temperature Science, Hokkaido University for his useful technical suggestions for processing the thin section of snow.

\section{References}

Coléou C., B. Lesaffre, J. B. Brzoska, W. Ludwig, E. Boller, 2001. 3-D snow images by $X$-rays micro-tomography. Ann. Glaciology, 32, 75-81.

Edelstein, W. A., E. M. Schulson, 1991. NMR imaging of salt-water ice. J. Glaciol., 37, 177-180.

Eicken, H., C. Bock, R. Wittig, H. Miller, H. O.

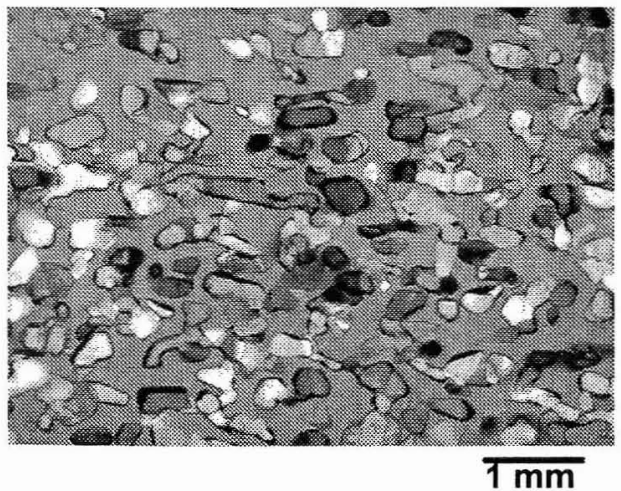

Figure 9: Thin section of small rounded mono-crystals.

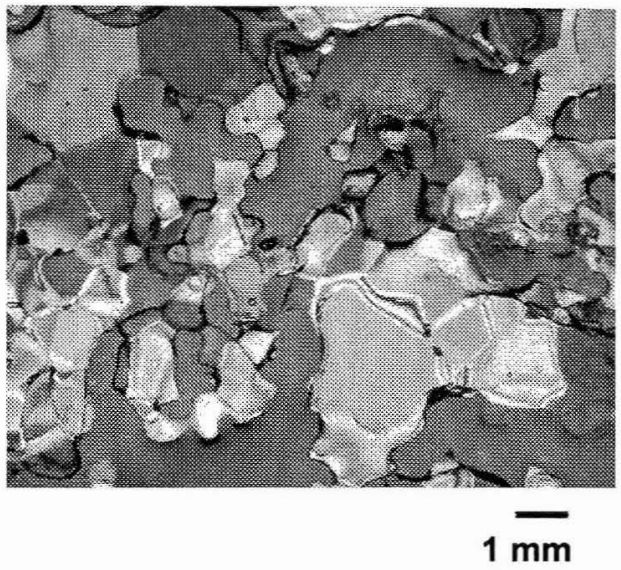

Figure 8: Thin section of large rounded poly-crystals.

Poertner, 2000. Magnetic resonance imaging of sea-ice pore fluids: methods and thermal evolution of pore microstructure. Cold Reg. Sci. Technol., 31, 207-225.

Hachikubo, A., H. Arakawa, K. Nishida, T. Fukuzawa, E. Akitaya, 2000. Section planes of snow specimens visualized with sudan black B. Polar Meteorol. Glaciol., 14, 103-109.

Kose, K., 1996. 3D NMR imaging of foam structures. J. Mag. Resonance, A118, 195-201.

Ozeki, T., A. Hachikubo, K. Kose, K. Nishimura, 2000. NMR imaging of snow. Proceedings of International Snow Science Workshop 2000, Big Sky, Montana, 402-406.

Schneebeli, M., 2000. Three-dimensional snow: How snow really looks like. Proceedings of International Snow Science Workshop 2000, Big Sky, Montana, 407-408.

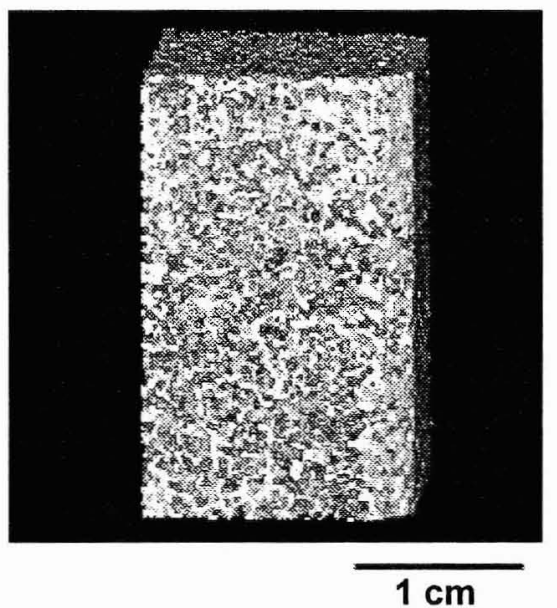

Figure 10: 3D display of small rounded mono-crystals (voxel size $120 \mu^{3}$ ). 